Open Access

\title{
A cross-sectional household cluster serosurvey of hepatitis $C$ virus antibodies in an urban slum of Cairo, Egypt in 2004
}

Isabelle A. Nakhla ${ }^{1}$, John W. Sanders ${ }^{2 *}$, Emad W. Mohareb', Sahar Samy ${ }^{3}$, Michael T. Cosby ${ }^{1}$, Manal M. Mostafa ${ }^{1}$, Mark S. Riddle ${ }^{1}$ and Robert W. Frenck Jr. ${ }^{4}$

\begin{abstract}
Background: Hepatitis C Virus (HCV) continues to be a burden to the Egyptian population and its economy. Despite all efforts, the prevalence of infection continues to be one of the highest in the world. The high national prevalence has been attributed to unintentional, nosocomial spread during an anti-schistosomiasis campaign conducted in the 1970's, but that does not fully explain the persistent infection rates. Work is needed to further clarify risk associations. A serosurvey was performed in Manshiet Nasser, a slum in Cairo sometimes referred to as Mokattem Hills where a primary occupation is garbage collection and sorting, to characterize potential risk factors for infection.

Methods: Following a detailed mapping and census of the area, a cluster sampling was performed and demographic and risk behavior data and a blood sample were collected from subjects older than 6 months. Blood samples were tested using $4^{\text {th }}$ generation anti-HCV EIA kit.

Results: The slum was estimated to house 45,000 residents. Blood samples were obtained from 2169 subjects. The age adjusted anti-HCV seroprevalence was $9.1 \%$. Participants with HCV antibodies were more likely to be male, heads of households, subjects without formal education, and those with a lower standard of living. After adjustment of all prevalence ratios (aPR) for age, the following risk factors were significantly associated with higher risk of HCV infection: Garbage collection (aPR 1.5), history of blood transfusion (aPR 2.0), tattooing (aPR 1.4), history of schistosomiasis (aPR 1.5), and use of traditional latrines (aPR 2.0) or pits for sanitation (aPR 1.3). The results of the multivariate analysis indicated that age $(p<0.01)$, history of schistosomiasis $(p<0.05)$, garbage sorting $(p=0.05)$, blood transfusions $(<0.001)$, and the use of traditional latrines for sanitation $(p<0.01)$ were significantly associated with infection.
\end{abstract}

Conclusion: While HCV prevalence among those over 30 could be attributed to anti-schistosomiasis injections, the prevalence in younger age indicates ongoing transmission. Although specific behavioral risks were not identified, HCV infection appears to be an occupational hazard of garbage collection and sorting in this environment. Given the large reservoir of HCV infection in the population, further effort needs to be made to identify and mitigate new infections.

Keywords: Hepatitis C virus, Prevalence, Risk factors, Cluster survey, Garbage collectors, Occupational exposure, Egypt, Slum, Needles, Tatoo

\footnotetext{
* Correspondence: jwsander@wakehealth.edu

${ }^{2}$ Wake Forest University School of Medicine, Medical Center Blvd., Winston-Salem, NC 27157, USA

Full list of author information is available at the end of the article
} 


\section{Background}

Hepatitis $\mathrm{C}$ virus $(\mathrm{HCV})$ infection is a well-recognized health problem throughout the world and particularly in Egypt. In contrast to an HCV seroprevalence of 1-2 \% in the United States and Europe and 0.1 to $5 \%$ in the Middle East, prevalence in Egypt ranges from 11 to $14 \%$ with the highest rates along the Nile River delta [1-9]. The Egypt Demographic Health Survey 2008 (DHS) showed a total prevalence of anti-HCV antibodies of $14.7 \%$ and detectable HCV RNA in $9.8 \%$. Prevalence was higher in men and rural governorates [10]. It has been suggested that the high prevalence of $\mathrm{HCV}$ in Egypt is related to contaminated needles used to administer tartar emetic as part of a campaign to eradicate schistosomiasis in the 1970's $[11,12]$. However, this cannot explain transmission among people born since 1980s, particularly in Cairo and Alexandria where large campaigns against schistosomiasis were not conducted. The epidemiology of HCV from the United States suggests that blood transfusions and intravenous drug use are major modes of transmission, but in Egypt, other modes of transmission such as sexual, intra-familial, and mother to child transmission, have been suggested as well $[1,13]$.

The Egyptian government recently announced a new strategic plan to address the HCV epidemic [14]. While a deal with the pharmaceutical company, Gilead, to provide their revolutionary new treatment at an affordable cost has received the most attention, the strategy also includes a plan to establish a national system to identify transmission trends and adapt responses as needed. A sentinel surveillance system was started in 2001 in five hospitals and identified ongoing transmission [15]. Unsafe medical injections, primarily through reuse of disposable syringes, was identified as a major risk factor [16], and hence much of the focus of the Egyptian government is to improve infection control practices in the health care system [14]. There is also significant interest in the role of vertical transmission [17]. However, other risk factors such as occupational exposures may be important as well. In order to better evaluate the epidemiology of ongoing HCV transmission in Egypt, we have re-evaluated data from a previously performed crosssectional survey designed to elucidate the risk factors and prevalence of HCV among a well-defined urban population of high-risk behavior garbage collectors in Cairo.

The study was conducted from 2003 to 2004 in a densely populated urban slum in Eastern Cairo known as Manshiet Nasser, sometimes also referred to as Mokattem Hills. The most common source of revenue for residents of the slum involves garbage collection so it has euphemistically been referred to as "garbage city." Traditionally, the men and boys have collected garbage from throughout the city, often including medical waste, bringing it back to the slum where the community sorts and recycles it, potentially exposing them to a wide array of infectious agents. It has attracted immigrants from other parts of the country and approximately one quarter of the families moved to the settlement after 1981 [18].

\section{Methods}

The community was mapped using high resolution diagrams to include details of each building. Each of the buildings and each of the units within the buildings was given a discriminate number. From the 2,258 buildings in the community, 15 were randomly selected and censused. This pilot survey found there to be an average of four family units per building and five people per family unit, resulting in an estimated population of the community of 45,000 persons.

Previous studies have estimated the prevalence of $\mathrm{HCV}$ in Cairo to be $8 \%$ [19]. Using cluster-sampling sample size calculation with a $99 \%$ confidence interval (CI) and a $2 \%$ margin of error, it was projected that 3136 subjects would need to be enrolled to adequately assess risk associations. Assuming a $70 \%$ participation rate, 4500 people would likely need to be approached to reach the targeted enrollment. Based on the pilot study and sample size estimate, every tenth building was selected to be included in the study and considered as one cluster. All households living in each building were visited and asked to participate in the study. If the household head refused to participate in the study, the next household within the building, as numbered during the mapping of the area, was approached. If all the families in the building refused to participate, the next adjacent building, as numbered during the mapping of the area, was approached for enrollment.

After verbal consent was provided, a socio-epidemiologic survey was performed with a detailed census of the household unit to include demographic characteristics of each member such as gender, age, education level, and occupation. Census information was entered into a computerized database allowing generation of a list of all members of each household that participated in the census and demographic questionnaire. These households were re-visited and each household member over 6 months of age was asked to donate a single sample of blood to be used for detection of antibodies to HCV (see below for methods). Subjects willing to participate in the serosurvey were also administered a structured clinical close-ended questionnaire. Information regarding history of an illness consistent with hepatitis, occupation, and presence of factors suspected of being associated with a higher risk of acquiring $\mathrm{HCV}$ were collected. Questionnaires were labeled with a personal identification number (PIN) to protect the 
confidentiality of the subject yet allow linkage to the blood samples.

A single $3 \mathrm{~mL}$ sample of blood was collected in a serum separator blood collection tube labeled with the subject's Personal Identification Number (PIN). After collection, the samples were allowed to stand at room temperature for $30 \mathrm{~min}$ to allow clot formation and then transferred to a cooler until transported to the Naval Medical Research Unit \#3 (NAMRU-3) lab at the end of the day. The lab was located approximately $20 \mathrm{~min}$ from the study site. At NAMRU-3, the serum was separated and frozen at $-70{ }^{\circ} \mathrm{C}$ pending testing.

Detection of $\mathrm{HCV}$ antibodies was performed using a $4^{\text {th }}$ generation anti-HCV EIA kit (Murex, London UK) as per the manufacturer's instructions. Positive and negative control wells were performed with each testing plate. For the test to be considered valid the mean negative control absorbance value had to be $<0.25$ and the mean positive control absorbance had to be $>0.8$ above the mean absorbance value of the negative control. Utilizing the manufacturer's kit instructions, a cutoff value was determined by adding 0.6 to the mean negative control absorbance results. The sample was considered reactive if its reading was higher than the cut off value. To check for false positive test results, reactive samples were re-tested in duplicate and those samples that were again above the cut off value in at least one of the two re-tested wells were presumed to have antibodies to HCV antigens. Samples that were non-reactive in both wells during the re-test were considered non-reactive.

Study subjects were provided a copy of their lab results. Those found to be anti-HCV positive were counseled regarding the infection as well as methods to prevent spread. Infected subjects also were offered liver function testing accompanied by coordinated referral for further testing (PCR) and management in Ministry of Health facilities where treatment would be offered at minimal expense.

All data was double entered into a Microsoft Access database and checked for consistency. Data analysis was performed using SAS v8.2 (SAS Institute, Carey, NC) and Stata v8 (Stata Corps, College Station, TX). Proportion of respondents and non-respondents were statistically compared using chi-square (Fisher's exact test when the data were sparsely distributed). For continuous variables difference between groups will be analyzed using $t$-test (Mann-Whitney when parametric assumptions were not met).

Stratum-specific age and gender seroprevalence was determined for the study population. In addition, the census results for the study population were used to estimate age- and gender-adjusted population anti-HCV seroprevalence for the population of the slum. Crude and adjusted prevalence ratios (PR) were calculated to assess the association between risk factors and anti-HCV seropositivity. To estimate the adjusted PR, logistic regression was performed using the generalized estimating equation [20] which enabled an adjustment for the correlation between respondents living within the same family and age effect $[21,22]$. After examining the effect of age on anti-HCV seroprevalence, age was stratified into three categories (0-12 years, 13-30 years, and 31 years and greater). Each risk factor and age category was then entered into an equation as independent variables with the anti-HCV positivity used as the dependent variable to check the effect of each risk factor alone. To arrange the risk factors according to their importance, all risk factors with significant effect on infection were entered into one equation with age and anti$\mathrm{HCV}$ status.

Although the entire community was considered to be economically depressed, questions were included in the household questionnaire intended to evaluate the family's standard of living. These questions included such items as home ownership, availability of some expensive and durable items such as indoor plumbing, a radio, a washing machine, an automobile, a television, etc. Positive answers to these questions were assigned one point and socio-economic status was expressed in scores based off the sums of these questions. Respondents in the lower quartile were considered to be poor relative to their community.

The study was reviewed and conducted as per ethical standards of the Institutional Review Board of the U.S. Naval Medical Research Unit \#3 (Cairo, Egypt) and in keeping with the guidelines of the US Department of Defense, which comply with the Helsinki Declaration of 1975.

\section{Results}

\section{Population survey and demographics}

Every tenth building was surveyed, and there were no refusals. The sample included 760 families with 3757 subjects residing in 248 buildings. See Fig. 1 for age and gender distribution. The mean age of the surveyed population was 23 years (range 6 months to 90 years, SD 16.1). Fifty-one and one half percent of the subjects were male, $28.1 \%$ did not receive any formal education, and $11.4 \%$ were working in garbage collection, sorting and/ or recycling. Of the total sample, $20.4 \%$ came originally from a rural governorate, while the remainder represented individuals from urban governorates $(23.0 \%)$ or Manshiet Nasser natives (56.6\%).

\section{Serosurvey demographics}

From 3757 subjects included in the census survey and asked to enroll in the study, 2180 (58 \%) respondents presented to the local area medical clinic for blood 


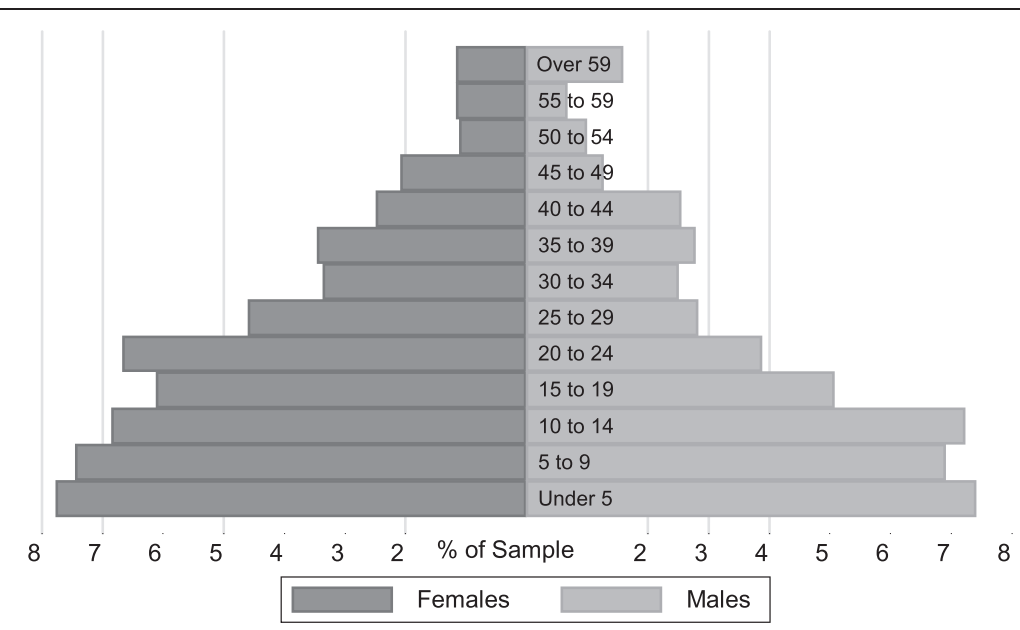

Fig. 1 Census Demographic Tree. Age and gender distribution of population assessed by the census of Manshiet Nasser, 2003

sampling and completion of the clinical questionnaire. For technical reasons, blood samples could be obtained from only 2169 (99.5\%). There were several differences among the group that contributed a blood sample and those that only participated in the initial census survey (Table 1). The mean age of participants was 21 years (95\% C.I. 20-22), 3 years less than the non-participants (24 years) (95 \% C.I. $24-25)(p=0.0001)$. The response among females (54\%) was higher than among males (46\%) in all age groups. The relative proportion of heads of the households to other family members was lower in the serosurvey participants compared to the nonparticipants. Participants were also more likely to be housewives and students, while manual and office workers were less likely to participate. Among subjects who were above the legal age of marriage in Egypt,

Table 1 Demographic characteristic differences between participants (submitted a blood sample) and non-participants (only completed census survey) in HCV serosurvey in Manshiet Nasser, 2003

\begin{tabular}{|c|c|c|c|}
\hline Socio demographic characteristics ${ }^{a}$ & Participants $n=2180$ & Non-Participants $n=1576$ & $p$-value* \\
\hline Mean Age (95 \% Cl) & $21(20-22)$ & $24(24-25)$ & 0.0001 \\
\hline Head of House Hold & $372(17)$ & $411(26)$ & 0.0001 \\
\hline Ever-Married & $841(65)$ & $679(60)$ & 0.003 \\
\hline \multicolumn{4}{|l|}{ Education } \\
\hline No education & $616(35)$ & $442(32)$ & 0.05 \\
\hline Primary and Preparatory & $831(47)$ & $555(40)$ & $<0.0001$ \\
\hline Secondary and above & $331(18)$ & $378(27)$ & $<0.0001$ \\
\hline \multicolumn{4}{|l|}{ Current work status } \\
\hline Not working & $265(15)$ & $201(15)$ & 0.9 \\
\hline House wife/Students & $965(55)$ & $545(42)$ & $<0.0001$ \\
\hline Garbage collector, sorter and recycler & $260(15)$ & $166(13)$ & 0.08 \\
\hline Manual laborer/drivers/shop workers & $233(13)$ & $332(25)$ & $<0.0001$ \\
\hline Office work & $27(2)$ & $69(5)$ & $<0.0001$ \\
\hline \multicolumn{4}{|l|}{ Origination } \\
\hline Upper Egypt (Rural) & $436(20)$ & $279(18)$ & 0.1 \\
\hline Lower Egypt (Rural) & $24(1)$ & $26(2)$ & 0.01 \\
\hline Urban Governorates & $401(18)$ & $460(29)$ & $<0.0001$ \\
\hline Born in Mokkattam & $1313(60)$ & $811(51)$ & $<0.0001$ \\
\hline Standard of living considered to be poor & $393(18)$ & $210(13)$ & $<0.0001$ \\
\hline
\end{tabular}


participants were more likely to be married compared to non-participants. A lower proportion of participants were Manshiet Nasser natives and with a lower and moderate standard of living than non-participants.

\section{Serosurvey results}

A total of 180 subjects were found to have antibodies to HCV resulting in a crude overall prevalence of $8.3 \%$ (Binomial exact $95 \%$ C.I. 7.2-9.5 \%). Among the serosurvey participants, the mean age for HCV positive subjects was 41 years (95 \% C.I. 39-43) and only 19 years (95\% C.I. 18-20) for the HCV negative participants $(p=0.0001)$ (Table 2). Prevalence increased gradually with age with a sharp increase in the age group 31 years and above $(\mathrm{PR}=54.6$, $p=<0.0001)$, a smaller peak at age 50 years, and a smooth decline thereafter (Fig. 2).
Marital status, education and governorate of origin

A positive $\mathrm{HCV}$ status was more prevalent among heads of households $(p<0.05)$, but not among those who had ever been married (even after adjusting for age). Subjects without formal education were more likely to have been infected $(p<0.05)$. Among HCV antibody positive subjects, the crude percent of subjects coming originally from Upper (Southern) Egypt was higher than those coming from Lower (Northern) Egypt, urban governorates, or Manshiet Nasser. After adjustment for age, the prevalence ratio was double for Lower Egypt compared to the urban governorates natives.

\section{Occupational risk factors}

As compared to non-working individuals, including housewives and students, the garbage collectors, sorters or recyclers, and those who had ever worked in relation

Table 2 Demographic characteristic differences between HCV-positive and HCV-negative volunteers in Manshiet Nasser, 2003

\begin{tabular}{|c|c|c|c|c|c|}
\hline \multirow[t]{4}{*}{ Demographic characteristics } & \multicolumn{5}{|l|}{$\mathrm{HCV}^{\mathrm{a}}$} \\
\hline & \multirow{3}{*}{$\begin{array}{l}\text { Positive } \\
\begin{array}{l}n=180^{\mathrm{b}} \\
n=(\%)\end{array}\end{array}$} & \multirow{3}{*}{$\begin{array}{l}\text { Negative } \\
n=1989^{\mathrm{b}} \\
n=(\%)\end{array}$} & \multirow{3}{*}{$\begin{array}{l}\text { Crude } \\
\text { Prevalence } \\
\text { Ratio (PR) }\end{array}$} & \multirow{3}{*}{$\begin{array}{l}\text { Adjusted } \\
\mathrm{PR}^{\mathrm{C}}\end{array}$} & \multirow[t]{3}{*}{$P$ Value } \\
\hline & & & & & \\
\hline & & & & & \\
\hline \multicolumn{6}{|l|}{ Age (years) } \\
\hline $0-12$ & 4/180 (2) & $818 / 1989(41)$ & 1 & & \\
\hline $13-30$ & 28/180 (16) & 764/1989 (38) & 7.0 & & $<0.001$ \\
\hline 31 and above & $148 / 180(82)$ & 407/1989 (21) & 54.6 & & $<0.0001$ \\
\hline $\operatorname{Mean}^{\mathrm{e}}(95 \% \mathrm{Cl})$ & $41(39,43)$ & $19(18,20)$ & & & \\
\hline Male & $89 / 180(49)$ & $903 / 1989(45)$ & 1.2 & $1.2(0.9-1.5)$ & NS \\
\hline Head of House Hold & $89 / 180(49)$ & 282/1989 (14) & 4.8 & $1.3(1.0-1.7)$ & $<0.05$ \\
\hline Ever-Married $^{d}$ & 155/172 (90) & $685 / 1112(62)$ & 5.3 & $1.1(0.6-2.1)$ & NS \\
\hline Respondents with no education ${ }^{\mathrm{e}}$ & $109 / 176(62)$ & $506 / 1599(32)$ & 3.2 & $1.4(1.1-1.9)$ & $<0.05$ \\
\hline \multicolumn{6}{|l|}{ Current work status } \\
\hline Not working/House wife/Students & 77/161 (48) & $1151 / 1587(73)$ & 1 & 1 & \\
\hline Garbage collector, sorter and recycler & $40 / 161(25)$ & 220/1587 (14) & 2.4 & $1.5(1.1-2.2)$ & $<0.05$ \\
\hline Manual laborer/drivers/shop workers & $41 / 161(25)$ & 192/1587 (12) & 2.8 & $1.3(0.9-1.8)$ & NS \\
\hline Office work & $3 / 161(2)$ & 24/1587 (2) & 1.8 & $0.7(0.3-1.9)$ & NS \\
\hline Ever sort garbage & $83 / 180(46)$ & $558 / 1989(28)$ & 2.1 & $1.7(1.3-2.2)$ & $<0.0001$ \\
\hline \multicolumn{6}{|l|}{ Previous residence } \\
\hline Upper Egypt & $86 / 179(48)$ & $348 / 1984(17)$ & 7.7 & $1.4(0.9-2.0)$ & NS \\
\hline Lower Egypt & $7 / 179$ (4) & 17/1984 (1) & 10.9 & $1.7(0.8-3.3)$ & NS \\
\hline Urban Governorates & $49 / 179(27)$ & 352/1984 (18) & 4.8 & $0.8(0.5-1.2)$ & NS \\
\hline Manshiet Nasser Natives & $37 / 179(21)$ & 1267/1984 (64) & 1 & 1 & \\
\hline Standard of living below community level & $42 / 180(23)$ & 348/1989 (18) & 1.4 & $1.4(1.0-1.9)$ & 0.05 \\
\hline
\end{tabular}

${ }^{\mathrm{a}}$ All results are $\mathrm{n}(\%)$ except for mean age $(\mathrm{Cl})$

${ }^{b}$ Numbers may not add up to (n) due to missing answers/eligibility to the question

${ }^{\mathrm{c}}$ Adjusted for age

${ }^{d}$ Ever married respondents in the age of marriage $(13+)$ were compared to never married respondents within the same age category

${ }^{\text {e}}$ Respondents greater than 6 years who have no education is compared to respondents greater than 6 years who have any education

${ }^{\mathrm{f}} \mathrm{NS}$ is not statistically significant 


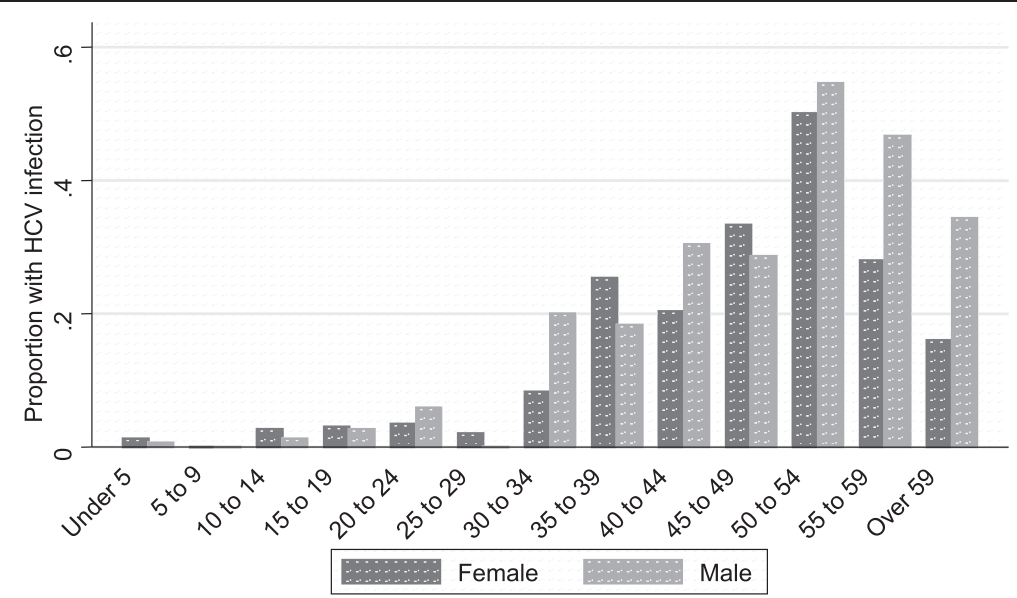

Fig. 2 Prevalence (\%) of HCV infection by gender and age group in Manshiet Nasser, 2003

to garbage at any time during their lives and manual laborers had the highest HCV seroprevalence (Table 2). Although garbage sorting as a profession was associated with $\mathrm{HCV}$ infection, none of the occupation-related risk behaviors (e.g. not wearing gloves while sorting garbage, coming across medical waste, or being ever stuck with a needle or a sharp object during sorting) was specifically associated with infection. After adjustment for age, garbage collectors, sorters, or recyclers were more likely to be seropositive compared to respondents who were

Table 3 Differences in self-reported potential risk factors for HCV acquisition between HCV-positive and HCV-negative volunteers in Manshiet Nasser, 2003

\begin{tabular}{|c|c|c|c|c|}
\hline \multirow[t]{4}{*}{ Probable risk factors } & \multicolumn{4}{|l|}{ Anti-HCV ${ }^{*}$} \\
\hline & \multirow{3}{*}{$\begin{array}{l}\text { Positive } \\
\mathrm{n}(\%) \\
n=(180)^{\mathrm{a}}\end{array}$} & Negative & \multirow{3}{*}{$\begin{array}{l}\text { Crude } \\
\text { P.R. }\end{array}$} & \multirow{3}{*}{$\begin{array}{l}\text { Adjusted }^{\mathrm{b}} \\
\text { P.R. (95 \% Cl.) }\end{array}$} \\
\hline & & \multirow{2}{*}{$\begin{array}{l}n(\%) \\
n=(1989)^{\mathrm{a}}\end{array}$} & & \\
\hline & & & & \\
\hline Previous surgery & $122 / 180(68)$ & $966 / 1989(49)$ & 2.1 & $1.3(1.0-1.7)$ \\
\hline Any medical procedure & 95/176 (54) & $588 / 1972(30)$ & 2.6 & $1.1(0.8-1.4)$ \\
\hline Previous dental work & 139/180 (77) & 993/1987 (50) & 3.2 & $0.9(0.7-1.3)$ \\
\hline Ever received blood transfusion & 23/176 (13) & $57 / 1981(3)$ & 3.9 & $2.0(1.5-2.8)^{*}$ \\
\hline Have any tattoos & 103/180 (57) & $927 / 1989(47)$ & 1.5 & $1.4(1.1-1.9)^{* *}$ \\
\hline Share razor blades & 10/89 (11) & 75/904 (8) & 1.3 & $0.7(0.4-1.3)$ \\
\hline Go to the barber & $89 / 89(100)$ & 858/893 (96) & $N / A^{c}$ & $N / A^{c}$ \\
\hline Ever have abortion/deliveries & $80 / 82(97)$ & $410 / 512(80)$ & 8.9 & $3.6(0.8-16.0)$ \\
\hline Received injection $>10$ injections & 130/179 (73) & 847/1986 (43) & 3.4 & $1.5(1.1-2.0)$ \\
\hline Reuse of needles for injections & $9 / 170(5)$ & $42 / 1681(2)$ & 2.0 & $1.0(0.5-1.7)$ \\
\hline Have ear/body piercing & $92 / 180(51)$ & 1063/1988 (53) & 0.9 & $0.9(0.7-1.1)$ \\
\hline Ever diagnosed of having Schistosomiasis & $39 / 177(22)$ & 109/1967 (6) & 3.8 & $1.5(1.1-2.1)^{* * *}$ \\
\hline Have a family member has HCV & $32 / 179(18)$ & 384/1960 (19) & 0.9 & $1.0(0.7-1.4)$ \\
\hline Individual at work known to have HCV & $11 / 168(7)$ & 104/1821 (6) & 1.1 & $1.0(0.6-1.6)$ \\
\hline Never sort garbage with gloves & 79/83 (95) & $534 / 558(96)$ & 0.9 & $0.8(0.4-1.7)$ \\
\hline Ever come across medical waste while sorting & 74/83 (89) & $489 / 558(88)$ & 1.2 & $0.8(0.5-1.4)$ \\
\hline Ever stuck by any sharp object while sorting & 77/83 (93) & $494 / 558(89)$ & 1.6 & $1.0(0.5-2.1)$ \\
\hline
\end{tabular}

${ }^{*} p=<.0001$

$p=<0.05$

$p=<0.01$

aNumbers may not add up to (n) or (100\%) due to missing answers/eligibility to the question

${ }^{\mathrm{b}}$ Adjusted for age

'Not applicable 
currently not working (aPR 1.5, $p<0.05$ ). In addition those who had ever sorted garbage were more likely to be seropositive than those who never sorted any garbage (aPR 1.7, $p<0.0001$ ).

\section{Medical risk factors}

A history of a surgical procedure or having received blood were associated with HCV seropositivity (Table 3). Thirteen percent of the anti-HCV positive subjects had a history of blood transfusion in contrast to only $3 \%$ of the negative subjects with an adjusted prevalence ratio (aPR) of $2.0(p<0.0001)$. Having had a tattoo was also significantly associated with anti-HCV positivity $(p<0.05)$. Self-reported procedures were further analyzed according to the place where they were performed. There was a trend toward dental work done in private clinics to be associated with anti-HCV positivity. Although circumcision was not generally associated with a greater risk of having $\mathrm{HCV}$, the procedure was significantly associated with $\mathrm{HCV}$ when performed in places other than a hospital $(p<0.0001$, data not shown).

Twenty-two percent of the HCV positive subjects reported a history of schistosomiasis infection, compared to $6 \%$ for those who were $\mathrm{HCV}$ negative, with an aPR of $1.5(p<0.01)$. The number of subjects reporting the receipt of injections for the treatment of schistosomiasis was too small for analysis.

A positive trend was also shown with the frequent use of injections. Seventy-three per cent of the anti-HCV positive subjects had a history of receiving more than ten injections during their life time.

\section{Living conditions}

Participants with lower standard of living relative to the community tended to be seropositive $(p=0.05)$ (Table 2$)$. However, among the living conditions measured, only the use of traditional latrines or using pits for sanitation ( $p<0.001$ and $p<0.05$, respectively) were found to be associated with seropositivity (Table 4). Using
Table 5 Multivariate analysis of demographic characteristics and risk behavior associated with HCV infection, Manshiet Nasser 2003

\begin{tabular}{lll}
\hline Demographic and risk factors* & PR $(95 \% \text { Cl })^{\mathrm{a}}$ & $p$ Value \\
\hline Age 13-30 & $14.4(2.0-104.5)$ & $<0.01$ \\
Age 31 and above & $125.5(17.2-915.1)$ & $<0.0001$ \\
Head of Household & $1.2(0.8-1.7)$ & \\
No formal education & $1.4(0.9-2.0)$ & \\
Standard of living considered to be poor & $1.2(0.7-1.9)$ & \\
Ever Sort Garbage & $1.5(1.0-2.4)$ & 0.05 \\
Ever get blood transfusion & $2.8(1.5-5.2)$ & 0.001 \\
Have any tattoos & $1.3(0.8-2.0)$ & \\
Ever diagnosed with schistosomiasis & $1.8(1.1-2.9)$ & $<0.05$ \\
Have a traditional latrine & $2.1(1.3-3.4)$ & $<0.01$ \\
\hline
\end{tabular}

*All variables with $p=0.05$ or lower were included in the multivariate model, the variable "Use covered pit/uncovered pit for sanitation" were dropped because it was affecting some of the other variables

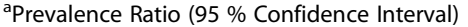

multivariate analysis, those using traditional latrines were 2.1 times more likely to have $\mathrm{HCV}(p<0.01)$ (Table 5).

\section{Multivariate analysis}

Results of multivariate analysis indicated that compared to the younger $(<13$ years $)$ participants, those $13-30$ years were 14.4 times more likely $(p<0.01)$ and those above 31 years were 125 times more likely to be $\mathrm{HCV}$ seropositive $(p<0.001)$. However, only the following risk factors were statistically significant: ever sorting garbage $(p=0.05)$, ever received a blood transfusion $(p<0.001)$, and ever diagnosed with schistosomiasis $(p<0.05)$ (Table 5).

\section{Discussion}

\section{Regional HCV prevalence}

The prevalence of HCV infection in Egypt, typically reported between 11 and $14 \%$, is among the highest in the world [23]. The Egypt Demographic Health Survey

Table 4 Differences in toileting facilities and crowding between HCV-positive and HCV-negative volunteers in Manshiet Nasser, 2003

\begin{tabular}{|c|c|c|c|c|c|}
\hline \multirow[t]{3}{*}{ Probable risk factors } & \multicolumn{2}{|l|}{$\mathrm{HCV}^{\mathrm{a}}$} & \multirow{3}{*}{$\begin{array}{l}\text { Crude } \\
\text { P.R. }\end{array}$} & \multirow{3}{*}{$\begin{array}{l}\text { Adjusted } \\
\text { PR }(95 \% \text { Cl) }\end{array}$} & \multirow{3}{*}{$P$ value } \\
\hline & Positive, n(\%) & Negative n(\%) & & & \\
\hline & $n=(180)$ & $n=(1989)$ & & & \\
\hline The floor is made of earth \& sand & $12 / 179(7)$ & $100 / 1984(5)$ & 1.4 & $1.0(0.6-1.7)$ & \\
\hline Traditional latrine & 148/179 (83) & 1384/1984 (70) & 2.0 & $2.0(1.4-2.9)$ & $<0.001$ \\
\hline Use covered pit/uncovered pit for sanitation ${ }^{c}$ & $63 / 179(35)$ & $537 / 1984(27)$ & 1.4 & $1.3(1.0-1.9)$ & $<0.05$ \\
\hline More than three persons per bedroom & $55 / 178(31)$ & $596 / 1978(30)$ & 1.0 & $1.2(0.8-1.6)$ & \\
\hline No hand washing facility & $36 / 179(20)$ & $326 / 1984(16)$ & 1.3 & $1.2(0.8-1.6)$ & \\
\hline
\end{tabular}

${ }^{a}$ Numbers may not add up to (n) or (100\%) due to missing answers/eligibility to the question

bPrevalence Ratio Adjusted for Age (95\% Confidence Interval)

cCompared to municipal 
(DHS) 2008 estimated the prevalence at $14.7 \%$ [10]. The seroprevalence in some of the neighboring eastern Mediterranean countries is much lower: Iran, $0.13 \%$ [5]; Saudi Arabia, 0.4 to 1.7 \% [8]; Syria, $0.95 \%$ [9]; Pakistan, 4.7 \% [7]; Libya, $1.2 \%$; Mauritania, $1.1 \%$; Algeria, $0.3 \%$; Morocco, $0.7 \%$; and, Tunisia $0.5 \%$ [6]. The prevalence in other large developing countries such as China $0.9 \%$ [24] and India $0.87 \%$ [25] are also much lower than in Egypt. Therefore, major efforts are required to investigate all possible risk factors that may explain this unique prevalence, both the traditional well described risk factors reported by many authors and other less traditional potential risk factors that may be unique to this country. Although the prevalence rates in the DHS 2008 show a decline from previously reported higher rates, our study showed a trend to continuous transmission that should warrant more study of the risk factors for continuous transmission in the Egyptian population.

\section{HCV prevalence in Egypt}

$\mathrm{HCV}$ infection varies significantly by region; an $8 \%$ rate of infection was found in Cairo and Alexandria compared to $15 \%$ in rural areas of the Nile Delta and Lower Egypt [26]. The age- and gender- adjusted prevalence rate of $9.1 \%$ reported in this surveillance is slightly higher than those reported for the general Cairo population from previous reports [10]. This difference may be attributable, among other factors, to socio-demographic determinants and occupation of participants. The census conducted prior to the initiation of the surveillance activities and among households provided an accurate representation of the total area population as all households participated in the census survey. The demographic differences between participants and non-participants in the serosurvey as compared to the census were noted. These differences could have resulted from the fact that the blood sampling was conducted during times when men were expected to be at work. House to house "mop up visits" were conducted on days when this population usually does not work, but the differences in participation were not completely resolved. Additionally, the refusal rate was higher than estimated. Despite these differences, we feel the study results are generalizable because of the homogeneous nature of the population in Manshiet Nasser and the even distribution of the population in regards to the social and demographic characteristics within each cluster.

Heads of households, usually males, were significantly fewer among participants while younger children were substantially greater. A possible explanation for higher child participation is that parents in the sampled population were keener to have their children tested, while refraining from desiring to know their infection status. According to some housewives among the participants, their men either knew or suspected they were positive and did not want to be tested. We hoped that counseling of the HCV-positive subjects and the other participants of the study would help the community take precautions and measures to avoid spread of the disease and seek treatment.

\section{$\mathrm{HCV}$ prevalence in young age and evidence of ongoing transmission}

The mean age for anti-HCV positive participants in our study was 41 years and there was a steady increase in prevalence of anti-HCV with age. These results are consistent with several other studies in urban and rural parts of Egypt [27-30]. The higher prevalence of anti-HCV in adults in our study might be attributed to iatrogenic transmission of the virus during historic schistosomiasis mass treatment campaigns in the 1970s $[12,26]$. We report that the prevalence of $\mathrm{HCV}$ differed among age groups and indicate a possible cohort effect, supporting the observation that continuous transmission of the virus occurs in Egypt [31, 32]. Although the age group representing the highest prevalence rates of infection are adults, $\mathrm{HCV}$ is more common than would be expected in the 10 to 25 years age group and in children under the age of 5 (Fig. 2). Comparatively, Miller et al. found that the 2010 incidence of this disease in Egypt is continuing at a rate of $\approx 6.9 / 1,000$ persons per year, indicating the possibility of continuous hyperepidemic transmission [32]. A relatively high seroprevalence in children may also indicate intrafamilial transmission of hepatitis $C$ [33].

\section{The spread of HCV infection through medical settings}

Multivariate regression analysis of demographic characteristics among participants indicated that age, history of schistosomiasis, garbage sorting, blood transfusions, and the use of traditional latrines or pits for sanitation are significantly associated with infection (Tables 4 and 5). Parenteral transmission through medical procedures, such as blood transfusion and frequent use of injections, is one of the key risk factors for the continuous transmission of $\mathrm{HCV}$ among the Egyptian population. This observation was noted by other authors [16, 34] and is supported by findings from other developing countries. A history of blood transfusion was reported in $26.1 \%$ of anti HCV positive patients in a large study from China [24] and in another population-based study from India, where history of reuse of disposable syringes accounted for $80.76 \%$ of HCV infections [25]. In Egypt, these exposures have been attributed to blood banks with inconsistent testing for $\mathrm{HCV}$ infection in the blood products before transfusion, the practice re-using needles to provide medical injections, and occupational exposure to 
accidental needle stick injuries [35]. These observations have led the Egyptian government and Ministry of Health to recognize the need to develop effective programs for monitoring and regulating the practice of invasive hospital procedures in the different levels of health care centers, with special emphasis on the primary and secondary health care centers in rural and underprivileged regions.

\section{Potential risk factors: garbage collection}

The occupation of garbage collection and sorting has never been reported as a risk factor for HCV infection, but it certainly exposes individuals living in this community to refuse collected from areas throughout greater Cairo. Healthcare facilities, including private clinics and offices, may be a source of unsterilized biohazardous medical waste. The study by Talaat et al. [35] found that $93 \%$ of healthcare workers in private healthcare facilities disposed of used needles in regular wastebaskets. Items such as needles, razor blades, and other discarded medical equipment may transmit the virus to people handling the waste. In our study, significant risk factors related to anti-HCV prevalence included the occupation of garbage collection and sorting. Although the lack of use of gloves as personal protective equipment during sorting was not found to be significantly associated with HCV infection in this study, the number of individuals who ever used gloves in this category may have been too low to make a comparable control group.

\section{Potential risk factors: use of traditional latrines or pits}

Among the other identified risk factors, the use of traditional latrines and pits for sanitation was similar to findings for Hepatitis B virus infection risks from a serosurvey conducted in Pakistan [36]. Since HCV is not known to be transmitted by fecal exposure, this observation may represent a surrogate for some other exposure. It is consistent with the finding of risk among the lower socioeconomic groups in this community.

The current surveillance study used a $4^{\text {th }}$ generation anti-HCV EIA kit for the detection of HCV antibodies. This method was used to demonstrate previous infection with HCV rather than the number of active cases such as in the DHS 2008 study which used both methods for Public Health Policy planning [10].

\section{Conclusion}

The results of this study affirm the public health importance of stopping transmission in urban as well as rural areas. The noteworthy finding that garbage collection is a risk factor for HCV transmission adds to the general understanding of the epidemiology of this disease. The identification of high risk target populations and activities is needed as part of the efforts to decrease transmission in Egypt. While HCV prevalence after the age of 30 could be attributed to anti-schistosomiasis injections, the prevalence in younger age indicates ongoing transmission. Our data seem to show that "vertical" transmission is not the key driver to continued elevated $\mathrm{HCV}$ prevalence in this population. Other factors are contributing to the ongoing transmission throughout life. These need to be clarified further as they provide an opportunity to intercede and decrease transmission.

The defined population represented by the Manshiet Nasser area of Cairo exists as a robust model for studying incidence and epidemiology of infectious diseases and is an invaluable population for future research. Given the large reservoir of HCV infection in the population, further effort needs to be made to identify and mitigate new infections.

\section{Future questions}

As highly effective but very expensive therapy becomes available, decision models for the most effective ways to interrupt the cycle of transmission need to be created. Further clarification of transmission risks among vulnerable populations is key to the creation of those decision matrixes.

\section{Competing interest}

Declaration of personal interests: None of the authors or staff who worked on the study has personal interests to declare. Declaration of funding interests: This study was funded by Interagency Agreement between NICHD, $\mathrm{NIH}$ and NAMRU-3.

\section{Authors' contributions}

IN, JS, and RF conceived of the study, participated in its coordination, and helped to draft the manuscript. SS coordinated field activities. EM conducted all serologic testing. MC, MM, and MR shared in statistical design, data management, and data analyses. All authors have contributed to the development, writing, review and final approval of the manuscript.

\section{Authors' information}

Not applicable.

\section{Acknowledgement}

The authors would like to thank the Viral and Zoonotic Diseases Research Program Laboratory, NAMRU-3 for testing the samples. We would like to thank Dr. Malla Rao, formerly at NICHD for his role in the funding agreement and the general design consultation for the study.

Thanks are also due to Ms. Maha El Sebai, last year medical student and summer trainee at NAMRU-3, for her efforts in reformatting of the manuscript and updated literature search.

\section{Authors' disclaimer}

The views expressed in this article are those of the authors and do not necessarily reflect the official policy or position of the Department of the Navy, Department of Defense, nor the U.S. Government. The authors declare that they have no competing interests.

The study was reviewed and conducted as per ethical standards of the Institutional Review Board of NAMRU-3 and in keeping with the guidelines of the US Department of Defense, which comply with the Helsinki Declaration of 1975. An informed consent was obtained from each participant or legal guardian for children below 18 years, as per protocol NAMRU3.2003.0002.

\section{Copyright statement}

Authors, except for Dr. Sahar Samy are employees of the U.S. Government. This work was prepared as part of their official duties. Title 17 U.S.C. §105 
provides that 'Copyright protection under this title is not available for any work of the United States Government.' Title 17 U.S.C. §101 defines a U.S. Government work as a work prepared by a military service member or employee of the U.S. Government as part of that person's official duties.

\section{Funding}

This study was funded through an Interagency Agreement between NICHD $\mathrm{NIH}$, and NAMRU-3.

\begin{abstract}
Author details
${ }^{1}$ Naval Medical Research Unit \#3, PSC 452, Box 5000FPO AE 09835-9998 Cairo, Egypt. ${ }^{2}$ Wake Forest University School of Medicine, Medical Center Blvd., Winston-Salem, NC 27157, USA. ${ }^{3}$ Egyptian Ministry of Health, Cairo, Egypt. ${ }^{4}$ Cincinnati Children's Hospital Medical Center, Cincinnati, USA.
\end{abstract}

Received: 14 June 2015 Accepted: 3 September 2015

\section{Published online: 01 October 2015}

\section{References}

1. Arthur RR, Hassan NF, Abdallah MY, el-Sharkawy MS, Saad MD, Hackbart BG, et al. Hepatitis $C$ antibody prevalence in blood donors in different governorates in Egypt. Trans R Soc Trop Med Hyg. 1997;91(3):271-4.

2. Arthur RR, Imam IZ, Saad MD, Hackbart BG, Mossad SB. HCV in Egypt in 1977. Lancet. 1995;346(8984):1239-40.

3. Group TGBoHCW. Global burden of disease (GBD) for hepatitis C. J Clin Pharmacol. 2004;44:20-9.

4. WHO. Hepatitis C, WHO fact sheet no.164. In: http://www.who.int/ mediacentre/factsheets/fs164/en/. 2000.

5. Kafi-abad SA, Rezvan H, Abolghasemi H, Talebian A. Prevalence and trends of human immunodeficiency virus, hepatitis B virus, and hepatitis $C$ virus among blood donors in Iran, 2004 through 2007. Transfusion. 2009;49(10):2214-20. doi:10.1111/j.1537-2995.2009.02245.x

6. Fadlalla FA, Mohamoud YA, Mumtaz GR, Abu-Raddad LJ. The epidemiology of hepatitis $C$ virus in the Maghreb region: systematic review and metaanalyses. PLoS One. 2015;10(3):e0121873. doi:10.1371/journal.pone.0121873.

7. Umar M, Bushra HT, Ahmad M, Data A, Khurram M, Usman S, et al. Hepatitis C in Pakistan: a review of available data. Hepat Mon. 2010;10(3):205-14.

8. Madani TA. Hepatitis C virus infections reported over 11 years of surveillance in Saudi Arabia. Trans R Soc Trop Med Hyg. 2009;103(2):132-6. doi:10.1016/j.trstmh.2008.08.001.

9. Othman BM, Monem FS. Prevalence of hepatitis C virus antibodies among intravenous drug abusers and prostitutes in Damascus. Syria Saudi Med J. 2002;23(4):393-5.

10. El-Zanaty F, Way A. Egypt Demographic and Health Survey 2008. Cairo, Egypt: Ministry of Health; 2009. El-Zanaty and Associates, and Macro International.

11. Medhat A, Shehata M, Magder LS, Mikhail N, Abdel-Baki L, Nafeh M, et al. Hepatitis $\mathrm{C}$ in a community in Upper Egypt: risk factors for infection. Am J Trop Med Hyg. 2002;66(5):633-8.

12. Rao MR, Naficy AB, Darwish MA, Darwish NM, Schisterman E, Clemens JD, et al. Further evidence for association of hepatitis $C$ infection with parenteral schistosomiasis treatment in Egypt. BMC Infect Dis. 2002;2:29.

13. Kalil KA, Farghally HS, Hassanein KM, Abd-Elsayed AA, Hassanein FE. Hepatitis C virus infection among paediatric patients attending University of Assiut Hospital. Egypt East Mediterr Health J. 2010;16(4):356-61.

14. WHO VIRAL HEPATITIS WORK GROUP W. Plan of Action for the Prevention, Care \& Treatment of Viral Hepatitis, Egypt 2014-2018. World Health Organization. 2014. http://www.emro.who.int/images/stories/egypt/ VH_Plan_of_Action_FINAL_PRINT1.pdf. 2015.

15. Talaat M, El-Sayed N, Kandeel A, Azab MA, Afifi S, Youssef FG, et al. Sentinel surveillance for patients with acute hepatitis in Egypt, 2001-04. East Mediterr Health J. 2010;16(2):134-40.

16. Talaat M, el-Oun S, Kandeel A, Abu-Rabei W, Bodenschatz C, Lohiniva AL, et al. Overview of injection practices in two governorates in Egypt. Trop Med Int Health. 2003;8(3):234-41

17. El-Kamary SS, Hashem M, Saleh DA, Ehab M, Sharaf SA, El-Mougy F et al. Reliability of risk-based screening for hepatitis $C$ virus infection among pregnant women in Egypt. J Infect. 2015. doi:10.1016/j.jinf.2015.01.009.

18. Awad L, Traboulsi O, Abu-habib L. Climb every mountain. New York: Links; 1998. p. 1-2
19. Frank C, Mohamed MK, Strickland GT, Lavanchy D, Arthur RR, Magder LS, et al. The role of parenteral antischistosomal therapy in the spread of hepatitis C virus in Egypt. Lancet. 2000;355(9207):887-91.

20. Inc. SI. The GENMOD procedures. In: Inc. SI, editor. SAS /STAT 9.2 User's guide Cary, NC, USA 2008.

21. Abu-Elyazeed R, Wierzba TF, Mourad AS, Peruski LF, Kay BA, Rao M, et al. Epidemiology of enterotoxigenic Escherichia coli diarrhea in a pediatric cohort in a periurban area of lower Egypt. J Infect Dis. 1999;179(2):382-9. doi:10.1086/314593.

22. MacKinnon DP, Krull JL, Lockwood CM. Equivalence of the mediation, confounding and suppression effect. Prev Sci. 2000;1(4):173-81.

23. Te HS, Jensen DM. Epidemiology of hepatitis $B$ and $C$ viruses: a global overview. Clin Liver Dis. 2010;14(1):1-21. doi:10.1016/j.cld.2009.11.009. vii.

24. Liu F, Chen K, He Z, Ning T, Pan Y, Cai H, et al. Hepatitis C seroprevalence and associated risk factors, Anyang, China. Emerg Infect Dis. 2009;15(11):1819-22. doi:10.3201/eid1511.090263.

25. Chowdhury A, Santra A, Chaudhuri S, Dhali GK, Maity SG, Naik TN, et al. Hepatitis $C$ virus infection in the general population: a community-based study in West Bengal, India. Hepatology. 2003;37(4):802-9. doi:10.1053/ jhep.2003.50157.

26. Strickland GT. Liver disease in Egypt: hepatitis C superseded schistosomiasis as a result of iatrogenic and biological factors. Hepatology. 2006;43(5):915-22.

27. Abdel-Aziz F, Habib M, Mohamed MK, Abdel-Hamid M, Gamil F, Madkour S, et al. Hepatitis C virus (HCV) infection in a community in the Nile Delta: population description and HCV prevalence. Hepatology. 2000;32(1):111-5.

28. Abdel-Wahab MF, Zakaria S, Kamel M, Abdel-Khaliq MK, Mabrouk MA, Salama $\mathrm{H}$, et al. High seroprevalence of hepatitis $\mathrm{C}$ infection among risk groups in Egypt. Am J Trop Med Hyg. 1994;51(5):563-7.

29. Darwish NM, Abbas MO, Abdelfattah FM, Darwish MA. Hepatitis C virus infection in blood donors in Egypt. J Egypt Public Health Assoc. 1992;67(3-4):223-36.

30. El-Sayed NM, Gomatos PJ, Rodier GR, Wierzba TF, Darwish A, Khashaba S, et al. Seroprevalence survey of Egyptian tourism workers for hepatitis B virus, hepatitis $C$ virus, human immunodeficiency virus, and Treponema pallidum infections: association of hepatitis $C$ virus infections with specific regions of Egypt. Am J Trop Med Hyg. 1996;55(2):179-84.

31. Barakat $\mathrm{SH}$, El-Bashir N. Hepatitis C virus infection among healthy Egyptian children: prevalence and risk factors. J Viral Hepat. 2011;18(11):779-84.

32. Miller FD, Abu-Raddad $L J$. Evidence of intense ongoing endemic transmission of hepatitis C virus in Egypt. Proc Natl Acad Sci U S A. 2010;107(33):14757-62. doi:10.1073/pnas.1008877107.

33. Mohamed MK, Abdel-Hamid M, Mikhail NN, Abdel-Aziz F, Medhat A, Magder LS, et al. Intrafamilial transmission of hepatitis C in Egypt. Hepatology. 2005;42(3):683-7.

34. Sharaf Eldin N, Ismail S, Mansour H, Rekacewicz C, El-Houssinie M, El-Kafrawy $\mathrm{S}$, et al. Symptomatic acute hepatitis $\mathrm{C}$ in Egypt: diagnosis, spontaneous viral clearance, and delayed treatment with 12 weeks of pegylated interferon alfa-2a. PLoS One. 2008;3(12):e4085. doi:10.1371/ journal.pone.0004085.

35. Talaat M, Kandeel A, El-Shoubary W, Bodenschatz C, Khairy I, Oun S, et al. Occupational exposure to needlestick injuries and hepatitis $B$ vaccination coverage among health care workers in Egypt. Am J Infect Control. 2003;31(8):469-74

36. Qureshi H, Bile KM, Jooma R, Alam SE, Afridi HU. Prevalence of hepatitis B and $C$ viral infections in Pakistan: findings of a national survey appealing for effective prevention and control measures. East Mediterr Health J. 2010;16(Suppl):S15-23. 